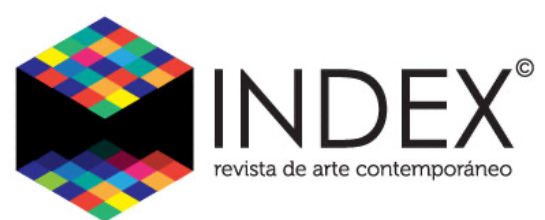

No. 10. DIC 2020.

Temas del arte

DOI: $10.26807 /$ cav.vi10.377

\title{
LA TUPI, UNA TÚPAC AMARU TRAVESTI: DISIDENCIA SEXUAL Y TRASGRESIÓN SIMBÓLICA EN EL FORO DE LA CULTURA SOLIDARIA.
}

THE TUPI, A TRANSVESTITE TUPAC AMARU: SEXUAL DISSIDENCE AND SYMBOLIC TRANSGRESSION IN THE SOLIDARITY CULTURE FORUM.

Jorge Alberto Miyagui Oshiro

\section{Resumen}

Para difundir las actividades del Colectivo ContraNaturas en el Foro de la Cultura Solidaria de Villa El Salvador en 2005, el artista visual Javi Vargas crea un diseño con la imagen de Túpac Amaru maquillado como travesti. Luego las ContraNaturas, con Javi Vargas como parte del colectivo, trabajan una propuesta de performance en base a la imagen del héroe maquillado, a este personaje apodan "la Tupi". Esta investigación analiza el surgimiento y la presencia de la Tupi en Villa El Salvador, la potencia simbólica del motivo y la trasgresión simbólica en el proceso creativo de Javi Vargas.

Palabras claves: La Tupi, Javi Vargas, Colectivo ContraNaturas, Foro de la Cultura Solidaria de Villa el Salvador, trasgresión simbólica, disidencia sexual

\section{Abstract}


To advertise the activities of ContraNaturas Collective at the Solidarity Culture Forum of Villa El Salvador in 2005, visual artist Javi Vargas created a design of a transvestite Túpac Amaru. Then ContraNaturas with the artist, as part of the collective, worked on a performance based on the image of this hero, wearing make-up, this character is nicknamed "The Tupi". This paper analyzes the rise and existence of Tupiin Villa El Salvador, the symbolic power of this motif, and the symbolic transgression in the creative process of Javi Vargas.

Keywords: The Tupi, Javi Vargas, ContraNaturas Collective, Solidarity Culture Forum in Villa El Salvador, symbolic transgression, sexual dissidence

\section{Biografía del autor}

Jorge Miyagui (Lima, Perú, 1978). Licenciado en Arte por la Pontificia Universidad Católica del Perú. Egresado de la Maestría en Historia del Arte Peruano y Latinoamericano por la Universidad Nacional Mayor de San Marcos. Ha realizado exposiciones individuales en Helsinki (Finlandia), Lima, Cusco y Chiclayo (Perú). Invitado como "Human Rights Advocacy Fellow-in-Residence" por el Trinity College en Connecticut (2015). Invitado en programas de la Universidad de Washington en Seattle (2009, 2011, 2015, 2017, 2019). Sus obras y textos aparecen en reseñas y publicaciones de distintos países: Perú, Chile, Argentina, Holanda, Finlandia y Estados Unidos. Ha sido miembro del Colectivo Aguaitones (1998-2001), del Foro de la Cultura Solidaria (2004-2009) y de la Brigada Muralista (2008-2019). Actualmente participa en los colectivos Centro Cultural El Averno y Museo Itinerante Arte por la Memoria (Premio Nacional de Artes y Ciencias en favor de los Derechos Humanos 2012 y Premio Príncipe Claus 2014). 
En el distrito limeño de Villa El Salvador, durante la tercera edición del Foro de la Cultura Solidaria $(\mathrm{FCS})^{1}$ el Colectivo ContraNaturas ${ }^{2}$ realizó performances que tenían como protagonistas a "las Tupis", personajes que representaban al héroe nacional Túpac Amaru como travesti. Las acciones tuvieron lugar en las afueras del Teatro Vichama y en al menos una discoteca. ${ }^{3}$ Junior Matamoros ${ }^{4}$ recuerda:

A la salida de una de las actividades del FCS estaban las Tupis con una bandera mostrando estadísticas no oficiales sobre discriminación y crímenes de odio. También usamos el Himno Nacional5 y el poema de "querrán matarlo y no podrán matarlo". ${ }^{6}$ Yo estaba de apoyo en aquella ocasión, 2006. Recuerdo que cuando pusimos el himno la gente que salía del teatro se paralizaba, hacía posición de firmes y hasta ponía su mano al pecho. Después salían las Tupis y empezaban a cuestionarse. Nosotras poníamos el Himno Nacional para que la gente se cuestione si las mariconas éramos ciudadanas o no. Las Tupis mostraban carteles con insultos de la sociedad hacia nosotros: "cabro sidoso", ${ }^{7}$ etc. En la discoteca fue casi lo mismo pero nos dimos cuenta que el público, que era nuestro público TLGB se empezaba a ofender. ¿Cómo es posible que digamos “cabro sidoso”? No entendieron la ironía. ${ }^{8}$

Esta acción tuvo su origen un año antes, en la segunda edición del FCS cuando las ContraNaturas organizaron una serie de actividades bajo el título Noches de Placer en el bar La Noche de Villa. El volante de difusión fue diseñado por Javi Vargas e impreso en formato A4, muestra en la parte central a Túpac Amaru con ojos maquillados y labios pintados, arriba se lee "Noches de Placer" seguido en letras más pequeñas por "Foro de la Cultura Solidaria". A los lados del personaje central se anuncian "performances, subversión, erotismo, chelas $^{10}$, transgresión, poesía, teatro, reflexión, caricias y música”. En la parte baja

\footnotetext{
${ }^{1}$ El FCS fue un espacio de encuentro para organizaciones y personas que apostaban desde las artes por la transformación social. Con el referente del Foro Social Mundial se organizaba una semana de actividades durante el mes de octubre en distintos lugares de Villa El Salvador: conciertos, conversatorios, exposiciones, talleres, murales, performances, obras de teatro, entre otras. Las seis ediciones del FCS se realizaron entre los años 2004 y 2009.

${ }^{2}$ Colectivo político de disidencia sexual activo aproximadamente desde finales de 2003 a 2012.

${ }^{3}$ Aunque Martín Jaime menciona que la performance se realizó en varias discotecas (Jaime, 2019, p.9798), Javi Vargas (J. Vargas, comunicación personal, 27 de septiembre de 2019) y Junior Matamoros (J. Matamoros, comunicación personal, 27 de octubre de 2019) creen que solo se llevó a cabo en una discoteca llamada La Búnker.

${ }^{4}$ Junior Matamoros fue integrante del Colectivo ContraNaturas.

${ }^{5}$ Jossy Cárdenas añade que después del Himno Nacional sonaba la canción de Gloria Trevi Todos me miran en cuyo vídeo clip aparece una travesti como protagonista (J. Cárdenas, comunicación personal, 15 de Noviembre de 2019).

${ }^{6}$ Se refiere a Canto coral a Túpac Amaru, célebre poema de Alejandro Romualdo que repite la frase "iy no podrán matarlo!"

7 "Cabro" es un término despectivo que en el Perú se usa para llamar al homosexual, al afeminado, al cobarde.

${ }^{8}$ J. Matamoros, comunicación personal, 27 de octubre de 2019.

${ }^{9}$ Artista visual integrante del Colectivo ContraNaturas.

${ }^{10}$ Término que refiere coloquialmente a las cervezas.
} 
se distingue a dos chicos que se besan mientras una travesti acaricia a uno de ellos, esta imagen está duplicada al espejo y ocupa todo el ancho del diseño. Sobrepuesto a este conjunto se informa los días, hora y lugar del evento. En la esquina inferior izquierda después de la palabra "Organiza" se ve el logo del Colectivo ContraNaturas y en la esquina inferior derecha bajo la palabra "Auspicia" el logo del bar La Noche de Villa. En letras muy pequeñas se lee en el extremo derecho y de manera vertical "basado en serie xx-tupas, Javier Vargas (2005)" ${ }^{11}$ En la contracara del volante se detalla la programación de las actividades del colectivo durante la semana del FCS 2005 (figura 1).

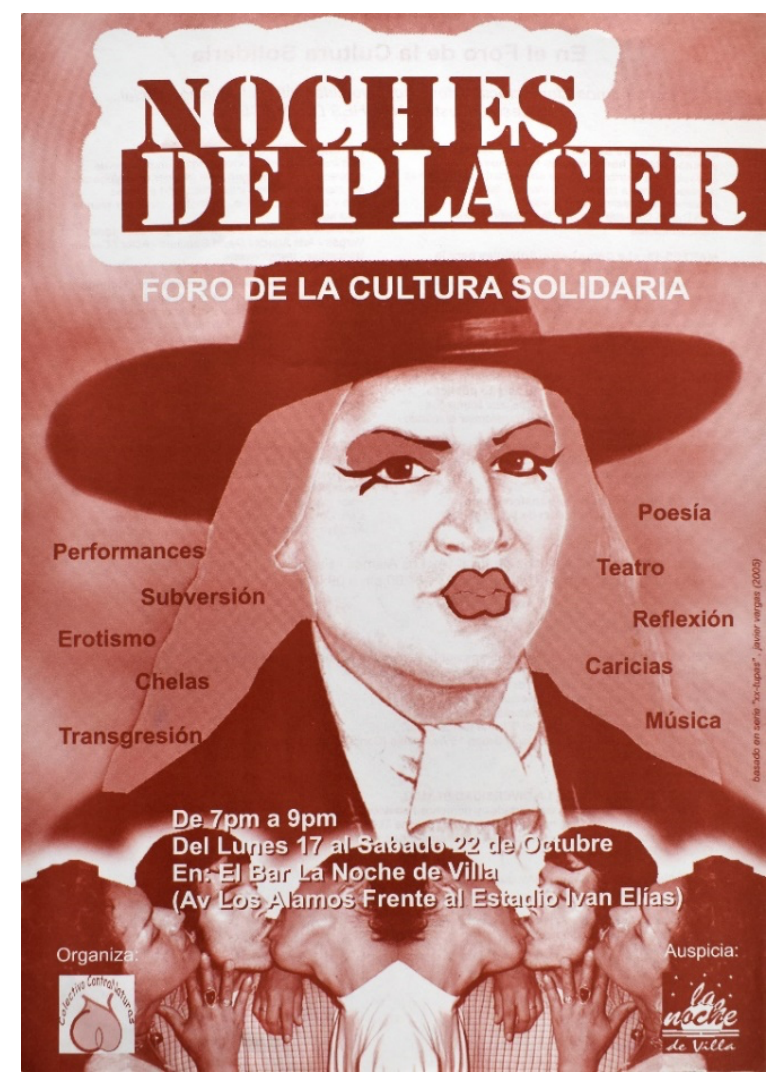

Figura 1. Afiche "Noches de placer" para promocionar las actividades del Colectivo ContraNaturas durante el II Foro de la Cultura Solidaria en Villa El Salvador 2005. Diseño: Javi Vargas.

\footnotetext{
${ }^{11}$ Javi explica que esta mención se refiere a fotomontajes porno con la imagen de Túpac Amaru y a otros ensayos de maquillaje sobre la imagen de Túpac Amaru los cuales se encontraba trabajando en ese tiempo (J. Vargas, comunicación personal, 2 de diciembre de 2019).
} 


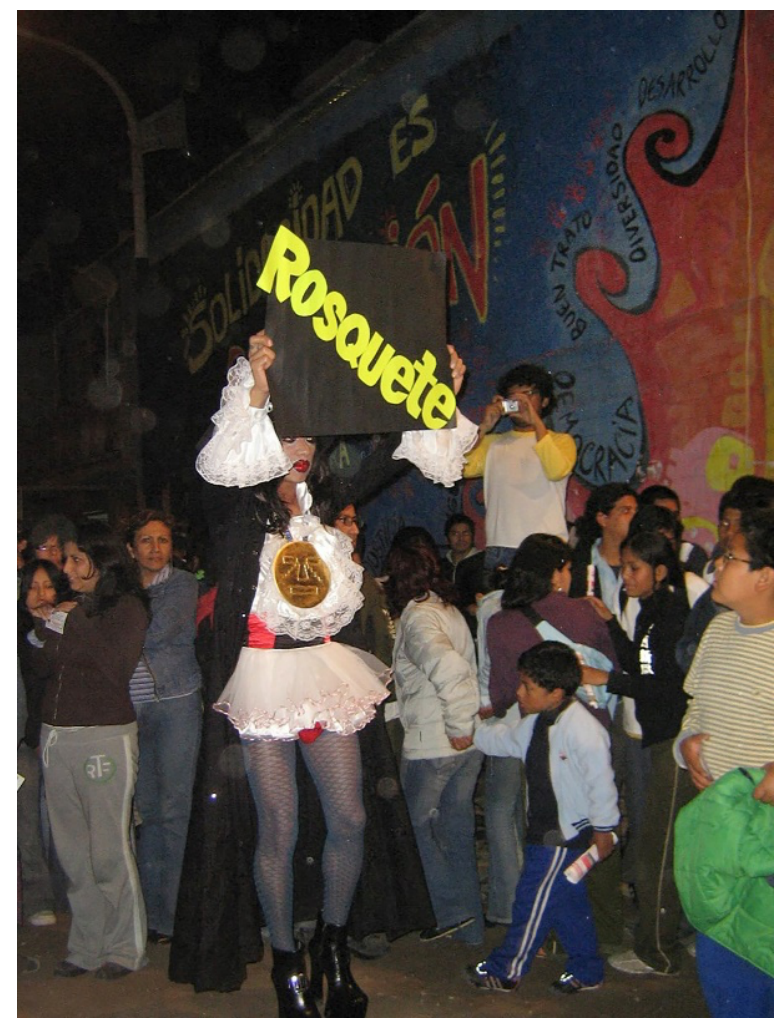

Figura 2. Registro fotográfico de acción de "Las Tupis" en las afueras del Teatro Vichama, durante el III Foro de la Cultura Solidaria en Villa El Salvador 2006.

Archivo: Colectivo ContraNaturas.

\section{Surgimiento de la Tupi y su presencia en Villa El Salvador}

Sobre el uso del apelativo "la Tupi” Jossy Cárdenas ${ }^{12}$ cuenta: "era la Túpac de Javi, yo fui quien le puso la Tupi y todos se rieron porque esas cosas salían: la Tupi, la Olli ${ }^{13} \ldots . .{ }^{14}$ Javi Vargas confirma que él llamó a sus piezas Las Túpacs y a una serie la tituló La falsificación de las Tupamaro ${ }^{15}$ pero "las ContraNaturas y otras cabras ${ }^{16}$ empiezan a llamarlas las Tupis”, le pareció un apodo bonito y lo aceptó como denominación. ${ }^{17}$ En la presente investigación uso el término "la Tupi” en su sentido amplio, para designar al

\footnotetext{
${ }^{12}$ Jossy Cárdenas fue fundadora del Colectivo ContraNaturas, es comunicadora social con experiencia en artes escénicas, fue parte del teatro universitario de la Universidad Nacional Mayor de San Marcos y llevó talleres con Barricada en Huancayo, Maguey y Yuyachkani. Como parte de la construcción colectiva de la performance con las Tupis, Jossy se encargó de los talleres internos de artes escénicas y Javi Vargas de los de artes visuales, tal como lo recuerda Jaime Ramos, integrante del colectivo quien encarnó junto con Andrés Espinoza y Ricardo Beretta a las Tupis en el FCS 2006 (J. Ramos, comunicación personal, 29 de octubre de 2019).

${ }^{13}$ La Olli hace referencia a Ollanta Humala, quien en esos años se presentaba como un candidato presidencial anti-sistema o anti-neoliberal y su símbolo político era una olla.

${ }^{14}$ J. Cárdenas, comunicación personal, 15 de Noviembre de 2019.

${ }^{15}$ Serie recientemente adquirida por el Museo Reina Sofia de Madrid.

${ }^{16}$ Apropiación afectiva del término despectivo "cabro".

${ }^{17}$ J. Vargas, comunicación personal, 27 de septiembre de 2019.
} 
motivo de Túpac Amaru travesti, trabajado gráficamente por Javi Vargas y como accionismo artivista por el Colectivo ContraNaturas.

La misma imagen del volante para Noches del Placer fue impresa en una banderola colocada en la fachada de La Noche de Villa. Durante uno de los días del evento las autoridades del distrito intentaron retirar la banderola argumentando falta de respeto a los símbolos patrios. Este incidente quedó registrado por Roberto de la Puente en el vídeo del FCS 2005. De la Puente recoge las declaraciones de Eduardo Juárez, integrante de ContraNaturas: "De ninguna manera les estamos faltando el respeto (...) simplemente está con sombras y con los labios pintados" ${ }^{18}$ En el vídeo se ve a Eliana Vigil, asistente al evento, discutiendo con la autoridad durante la intervención, ella cuenta que la policía fue dos veces, en la segunda ocasión llevaron una Constitución Política del Perú y dijeron que faltar el respeto a un símbolo patrio era delito. Eliana recuerda que se querían llevar la banderola y que la intervención de César Escuza, director del Teatro Vichama fue fundamental para que esto no sucediera y el evento pudiera continuar, ya que se contaba con una autorización municipal o existía alguna relación con la municipalidad. ${ }^{19}$ Javi Vargas comenta el incidente:

La hipótesis de la Paul ${ }^{20}$ y lo dijo esa noche en el evento, es que el MRTA ${ }^{21}$ ha tenido presencia importante en Villa El Salvador y eso puede significar que ese frente se mantiene, siendo probable que hayan estado como participantes sentados en el evento. La Paul era bien pendeja para darse cuenta de las cosas y cree que alguien ha tenido que pasarle la voz al gobernador para que llame a la policía. De hecho, en el evento dijo: "Es increíble cómo hay gente que se indigna porque a Túpac Amaru le pintan los labios y sin embargo no se indigna que haya un grupo que utilice su imagen para matar gente". No mencionó la palabra MRTA pero sabíamos a qué se estaba refiriendo. ${ }^{22}$

\footnotetext{
${ }^{18}$ De la Puente, 2019, 10:39.

${ }^{19}$ E. Vigil, comunicación personal, 2 de julio de 2020.

20 Paul Flores, también conocida como "Ana Paula". Activista y miembro fundador del Colectivo ContraNaturas. Fallece en diciembre de 2015.

${ }^{21}$ El 31 de mayo de 1989 el Movimiento Revolucionario Túpac Amaru (MRTA) asesinó a ocho personas gays y travestis en el bar Las Gardenias, en Tarapoto. Por esta razón en dicha fecha se celebra el Día Nacional de Lucha Contra la Violencia y los Crímenes de Odio hacia Lesbianas, Trans, Gays y Bisexuales. 22 J. Vargas, comunicación personal, 27 de septiembre de 2019.
} 
Marco Rodríguez ${ }^{23}$ agrega sobre las tensiones producidas: "vino gente de civil antes del incidente a amenazar. La cosa fue tensa porque chocó con la autoridad y parte de la población”24. Por su parte, César Escuza testimonia:

Les dije que teníamos una autorización municipal y que no podían meterse acá, vayan a hablar con su alcalde. Estábamos en nuestro derecho, pero la pregunta era ¿Cuál es el problema? ¿Qué es lo que no se debe hacer? Hasta que alguien dijo: “¿Es que le han pintado los labios a Túpac Amaru!”. ${ }^{25}$

Estos sucesos fueron muy importantes para el desarrollo de las acciones performativas presentadas en 2006. Junior Matamoros comenta:

A partir del incidente del 2005 con el Túpac Amaru maquillado pensamos qué se podía hacer con esta imagen. Si el espacio era un espacio anticapitalista y de izquierda la propuesta tenía que estar relacionada a esas demandas. Uno de los objetivos políticos era cuestionar la hegemonía de la lógica masculina y heterosexual porque en muchos espacios donde íbamos, no solo el FCS, quienes tenían el protagonismo eran hombres y heterosexuales. No se pensaba que nuestras agendas eran legítimas o nuestras agendas no se entrelazaban con otras agendas, como el tema del agua o el movimiento indígena porque antes de nosotras ser mariconas también debíamos luchar por el agua. ${ }^{26}$

Jossy Cárdenas dice:

Para nosotros fue importante porque dijimos: "Ah, acá hay algo potente". Esto coge carne con lo del 31 de mayo el MRTA ejecutando a travestis. Para nosotros todo tenía relación y también con el discurso que leyó Paul en Tambogrande ${ }^{27}$ que se llamaba Juntos y también revueltos ${ }^{28}$. Eso fue fundante porque nosotros necesitábamos incomodar incluso al compañero. ${ }^{29}$

También, durante el 2006 se organizó una nueva edición de Noches de Placer esta vez en el auditorio de la FEPOMUVES,$^{30}$ instalando un toldo cerrado en donde se realizaron conferencias. En la fachada se colocó una banderola con un nuevo diseño de Javi

\footnotetext{
${ }^{23}$ Marco Rodríguez fue militante de varias organizaciones que participaron en la organización del FCS.

${ }^{24}$ M. Rodríguez, comunicación personal, 4 de diciembre de 2019.

${ }^{25}$ C. Escuza, comunicación personal, 16 de noviembre de 2019.

${ }^{26}$ J. Matamoros, comunicación personal, 27 de octubre de 2019.

${ }^{27}$ En el contexto del Foro Social Mundial distintas organizaciones sociales y políticas impulsaron un Foro Social Perú, iniciativa en la que participaron muchas personas que activaron luego en el Foro de la Cultura Solidaria. Se participó en el Foro Social de las Américas en Quito y luego en el Encuentro Grande en Tambogrande. Hacia el Foro Social Perú, ambos eventos tuvieron lugar entre julio y agosto de 2004.

${ }^{28}$ El texto afirmaba la apuesta por transversalizar las distintas agendas de lucha. Tambogrande era un referente de resistencia campesina frente al capital minero pero la dirigencia no estaba libre de homofobia ni veía a las organizaciones TLGBI como un movimiento político. La presencia de Paul Flores en la mesa final del encuentro generó tensiones, finalmente pudo leer el pronunciamiento.

${ }^{29}$ J. Cárdenas, comunicación personal, 15 de Noviembre de 2019.

${ }^{30}$ Federación Popular de Mujeres de Villa El Salvador.
} 
Vargas y otra banderola similar fue ubicada en el toldo al interior del auditorio. Las banderolas mostraban una versión del Túpac Amaru maquillado esta vez con torso masculino desnudo y un Sagrado Corazón de Cristo en el pecho. Para el FCS $2009^{31}$ las ContraNaturas participan con una versión actualizada de la performance ya no fuera del Teatro Vichama como en el 2006 sino dentro, como parte del evento Acción política desde la tierra y la libertad (figura 2). Una mirada desde el arte organizado por activistas del FCS que estaban formando el partido político Tierra y Libertad. Quienes encarnaron a las Tupis en esta ocasión fueron: Jaime Ramos, Rafael Alarcón y Joshua Gálvez-Durand. ${ }^{32}$ Esta vez una de las Tupis caía muerta y las otras la cubrían con periódicos haciendo referencia a los crímenes de odio. Javi recuerda que también se leyó el poema de Romualdo y que se levantaron carteles con frases homofóbicas. ${ }^{33}$ En la última edición del FCS la Tupi también se hizo presente en un mural ${ }^{34}$ y en una exposición de artes visuales. ${ }^{35}$

\section{Transgresión simbólica en la obra de Javi Vargas}

La primera aparición de la imagen de Túpac Amaru en el proceso creativo de Javi Vargas se da con un videoarte en 2003. Javi utilizó muñecos de Ken y Barbie para narrar la

\footnotetext{
${ }^{31}$ No he podido rastrear presencia de la Tupi en las ediciones del FCS 2007 y 2008. Según los programas de actividades las ContraNaturas presentan solo dos actividades en el 2007 y no participan en el 2008.

32 J. Vargas, comunicación personal, 16 de agosto de 2020

${ }^{33}$ J. Vargas, comunicación personal, 27 de septiembre de 2019.

${ }^{34}$ Como parte de las actividades previas a la semana del FCS se realizó un mural comunitario en el Estadio Iván Elías ubicado en la avenida Los Álamos. Estuvieron presentes las ContraNaturas, el colectivo Ambre, el colectivo La Sucia, la Brigada Muralista y activistas varias. En el vídeo registro de la actividad realizado por Ramiro García, Javi Vargas declara: "estamos planteando el personaje de la Tupi, un Túpac Amaru travesti y vamos a ver qué tal nos va y cómo es la interacción con el público. Va a quedar bien maricona" (García, s.f., 3:50).

${ }^{35}$ Exposición organizada por el Museo Itinerante Arte por la Memoria en el Teatro Vichama. Allí se expone una banderola donde aparece la Tupi con traje amazónico y la frase "Unidas contra el odio. Por mis tacos, mi tierra y mi agua. Colectivo ContraNaturas" junto al logo del colectivo. La banderola se realizó para participar en la Marcha del Orgullo llamando la atención sobre los sucesos ocurridos el 5 de junio de ese año en la región amazónica de Bagua. La población nativa que protestaba contra decretos legislativos que afectaban sus territorios se enfrentó a las Fuerzas Armadas produciendo 33 personas muertas y una desaparecida. La banderola respondió a tensiones producidas en una asamblea de los grupos LGTBI para coordinar la Marcha del Orgullo, Paul Flores sostenía que la marcha tenía que relacionarse con lo sucedido en Bagua. Mucha gente se opuso argumentando que no se debía "politizar" la marcha (J. Vargas, comunicación personal, 27 de septiembre de 2019). En la muestra, además de la banderola, las ContraNaturas presentaron una instalación a partir de dos diseños de Javi, uno de ellos ya mostrado en la fachada de la FEMOMUVES durante la edición del FCS 2006. Los diseños estaban impresos digitalmente sobre superficies duras y fueron colocadas en el suelo sugiriendo los rastros de una acción violenta, junto a una silla derribada y pedazos de ladrillos rotos. Javi comenta que la idea surgió allí mismo con los materiales que tenían disponibles (J. Vargas, comunicación personal, 27 de septiembre de 2019).
} 
historia de un Túpac Amaru brichero ${ }^{36}$ junto a chicas rubias sobre un escenario. Se evocaba el vídeo clip de la canción Material Girl de Madonna, que a su vez referencia la presentación de Marilyn Monroe cantando Diamonds are a girl's best friend. La trasgresión de Javi reside en cuestionar las construcciones simbólicas anteriores de Túpac Amaru, Javi afirma que ya ese Túpac Amaru "era cabro, la idea era hacer expresar modos de sexualidad denegadas en las representaciones hegemónicas". ${ }^{37}$

El Túpac Amaru de Javi fue desarrollándose desde su versión audiovisual como brichero a versiones gráficas. Aún conserva una serie de dibujos realizados en 2004, delineados por él y coloreados por el ilustrador José Ronceros. En los dibujos Túpac Amaru aparece siempre maquillado y con el tradicional sombrero de ala ancha. Uno de los dibujos parodia el cuadro Las dos Fridas de la pintora mexicana Frida Kahlo y muestra dos versiones de Túpac Amaru con torsos desnudos tomados de la mano, con pantalonetas cortas ajustadas que dejan ver la erección de sus penes, uno de ellos parece estar masturbándose. Ambos personajes tienen en el pecho la imagen del Sagrado Corazón de Jesús. Otro de los dibujos muestra a Túpac Amaru como sirena sosteniendo una pistola y reposando sobre un plato con la palabra “invisible” (figura 3). En otro dibujo se puede ver al héroe con el uniforme de la selección peruana de fútbol, tomando una pelota, usando velo y bouquet de novia con los textos "boy toy" "like a virgin". ${ }^{38}$ También aparece Túpac Amaru convertido en un niño con el Sagrado Corazón de Jesús sobre el pecho, sentado entre un padre tocándose el pene y una madre. En otra de las imágenes el héroe, con otra travesti mira curiosas a un vigilante uniformado quien muestra su trasero. En una línea más telúrica, un último dibujo de la serie muestra a Túpac Amaru con el torso desnudo entre hojas y ramas con la frase "Mujer y naturaleza. Vida que se renueva".

\footnotetext{
${ }^{36}$ Término coloquial que se origina de la palabra inglesa bridge (puente) usado para referirse a quien utiliza sus rasgos fenotípicos indígenas para tener relaciones con personas extranjeras en una lógica de autoexotización. El título del vídeo es justamente Brichero.

${ }^{37} \mathrm{~J}$. Vargas, comunicación personal, 2 de julio de 2020.

${ }^{38}$ Claras referencias a la cantante Madonna.
} 


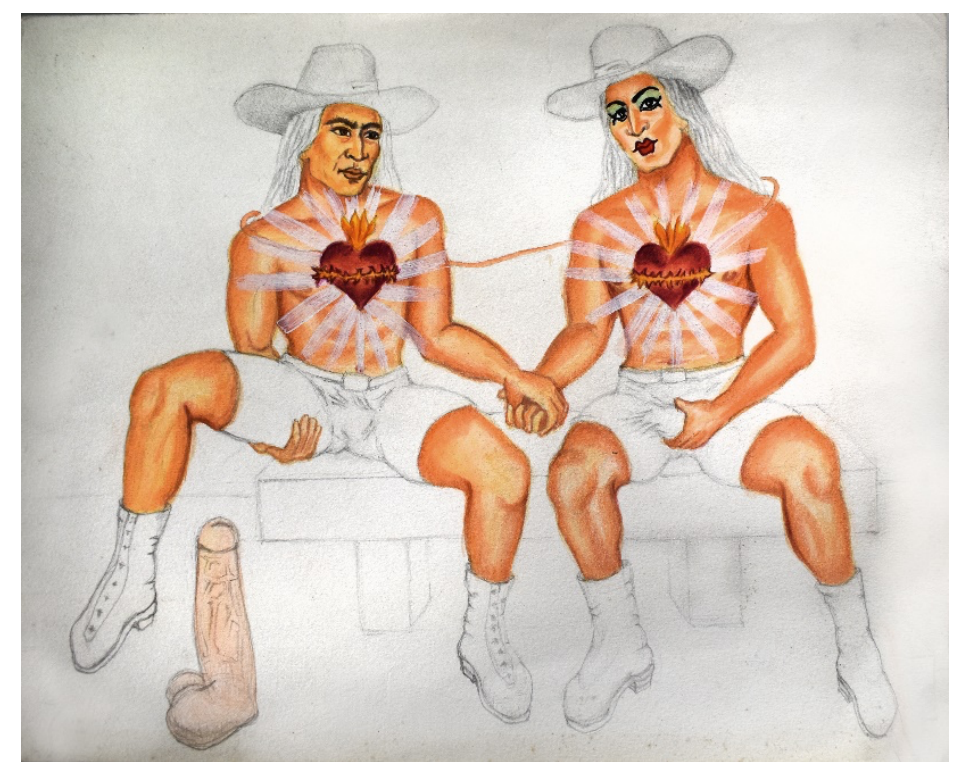

Figura 3. Dibujo de Javi Vargas coloreado por José Ronceros. 2004. Archivo: Javi Vargas.

Entre otras trasgresiones icónicas en el arte están el llamado “Zapata gay” del pintor mexicano Fabián Cháirez (2019), el retrato de Simón Bolívar travesti del pintor chileno Juan Domingo Dávila (1994) y en nuestro medio las intervenciones a la imagen de Santa Rosa de Lima trabajadas por el Grupo Chaclacayo en los ochenta. El recurso de la trasgresión en la obra de Javi está presente desde su periodo universitario. En aquellos años, para el curso que dirigía la profesora María Burela, Javi realizó junto a Eddy Calle ${ }^{39}$ una instalación con imágenes porno de hombres mostrando el ano. Esta instalación derivó en un proyecto individual de Javi en base a montajes digitales, uniendo el rostro de un jugador de fútbol peruano a cuerpos de actores porno. Mucho después, entre julio y agosto de 2009 Javi realiza su primera individual en la Galería L'Imaginaire de la Alianza Francesa de Miraflores. A una semana de la inauguración la institución retiró una de las piezas. El Colectivo ContraNaturas circuló una carta con firmas en rechazo a la censura:

La mencionada obra consiste en un vídeo cuyos protagonistas son "Las Túpac" y "La San Martín" (héroes de la patria travestidos) disfrutando un encuentro sexual sugerido, que ni siquiera encajaría en la categoría de adultos, puesto que no existe ningún desnudo. ${ }^{40}$

¿Cómo se solucionó el impase? Javi detalla:

La exposición se inauguró sin novedad, creo que fue bien acogida sobre todo por el movimiento LTGBI y a la semana me llamaron para avisarme que una

\footnotetext{
${ }^{39}$ Luego Eddy Calle, Javi Vargas y María Burela formarían parte del colectivo Aguaitones.

${ }^{40}$ Colectivo ContraNaturas, 10 de agosto de 2009.
} 
de las piezas estaba siendo retirada porque era una institución educativa y habían menores de edad. Era un vídeo en el cual se veía a las Tupis, una se masturbaba con la imagen de Túpac Amaru y luego venían varias Tupis y simulaban una orgía, no había escenas explícitas. Yo estaba pensando retirar la exposición y convenimos que ponían un letrero gracioso que decía "mayores de 18, prohibido para los niños". Después de la reposición hubo una mesa de conversación sobre la censura, (...) las Tupis hicieron una performance. ${ }^{41}$

Actualmente Javi se encuentra alejado del movimiento LGTBI por considerar que, como muchos movimientos de resistencia, en buena medida ha sido cooptado por las políticas neoliberales produciendo aburguesamiento y des-radicalización. Javi afirma que un gran sector de la población LGTBI, identificándose con valores tradicionales burgueses, dice: "nosotros no nos prostituimos, somos gente decente". ${ }^{42}$

Para ese entonces (2012) había llegado a mi crisis con respecto al movimiento LTGB, habían pasado muchas cosas y yo me sentía decepcionado, cuestiones de aburguesamiento y domesticación de muchos de los grupos con los cuales alguna vez me alié. Ese mismo aburguesamiento emergió cuando hice esta acción. El ańo pasado (2011) algunos chicos se reunieron para besarse en la Plaza Mayor, fue una experiencia muy intensa ${ }^{43}$. $\mathrm{Al}$ año siguiente se hizo una nueva convocatoria pero en clave muy burguesa para recordar eso que ocurrió. Los organizadores querían que todo fuera con permiso, no había espacio para la exploración fuera de lo normado y además era evidente a dónde íbamos: la cooptación neoliberal del movimiento, eso ya ocurre en el mundo anglosajón, es un movimiento funcional al capitalismo. Como yo veía eso hice una performance que consistía en quemar la bandera del orgullo. El fuego lo entiendo de una manera ambivalente: la bandera del orgullo es una metáfora del arco iris, que es el efecto del fuego: el sol con las gotas de lluvia. Quemé la bandera y me bajé el pantalón, una clave muy anarquista. Después vino una caza de brujas contra mí, la mayor parte de grupos me insultaron, que debían quemarme a mí, que por qué no pedí permiso (...). De allí me alejé del movimiento, pero en cualquier momento podría articular alguna acción si es necesario, además han emergido nuevas voces. ${ }^{44}$

\section{Potencia simbólica de la Tupi}

Para entender el impacto de la Tupi hay que comprender la trascendencia de la imagen de Túpac Amaru en nuestro medio y revisar el peso de su construcción visual en

\footnotetext{
${ }^{41}$ J. Vargas, comunicación personal, 27 de septiembre de 2019.

42 J. Vargas, comunicación personal, 27 de septiembre de 2019.

${ }^{43}$ La imagen de Javi besándose con el activista conocido como Gio Infante había sido reproducida en muchos medios de comunicación.

${ }^{44}$ J. Vargas, comunicación personal, 27 de septiembre de 2019.
} 
capas de memorias sucesivas. Sobre José Gabriel Condorcanqui Noguera se ha escrito bastante, conocido como Túpac Amaru II, encabezó la más grande rebelión contra la colonia española en el siglo XVIII y provocó posteriormente una gran represión militar, política y cultural. La figura de Túpac Amaru ha acompañado la formación cívico-patriótica de distintas generaciones peruanas durante décadas y sin embargo no siempre tuvo ese lugar privilegiado en el panteón de héroes y heroínas nacionales. Charles Walker da cuenta de la fluctuación en la importancia simbólica de Túpac Amaru, desde apariciones intermitentes en las memorias locales hasta llegar a convertirse en símbolo nacional e incluso internacional, por ejemplo, en Argentina "se presentó una obra (...) titulada Tupac Amaru en 1821 y se recibió a Juan Bautista Tupac Amaru en 1822” (Walker, 2015, p. 244). Aunque la imagen había estado presente anteriormente en procesos reivindicativos como la fallida Ley de Reforma Agraria del gobierno de Fernando Belaúnde Terry en 1964, Walker ubica el momento clave para la gran reivindicación del rebelde en el Gobierno Revolucionario de las Fuerzas Armadas encabezado por Juan Velasco Alvarado (1968-1975), el cual convirtió a Túpac Amaru en símbolo de los procesos de transformación social que emprendió, proyectándolo como precursor de la Independencia (Walker, 2015, p.244). Javi Vargas centra el valor de la Tupi en el acto de travestir como forma de re-significación positiva:

Para mí no es un acto de denigración, como se asume en la subjetividad machista, homofóbica, misógina, heteronormativa, transfóbica. Por eso en los medios de comunicación si quieren atacar a alguien lo travisten. Mi trabajo va a contracorriente de eso porque de alguna manera el travestir es volver un ser mágico. No me gusta usar palabras como ennoblecer, enaltecer pero de alguna manera es como convertirlo en un personaje mágico, fantástico, con otra clase de poder y subjetividad. Por eso el personaje que elijo para travestir tiene muchas cualidades a resaltar, siempre en una clave de lo contradictorio también. Por ejemplo, con Velasco ${ }^{45}$ lo admirable es que confrontó todo un sistema oligárquico y trató de construir un sistema político a contracorriente, rompiendo un orden jerárquico de cómo se habían naturalizado los cuerpos en un sistema brutalmente racista. Pero por otra parte desde la clave de la sexualidad, algunas cosas son contradictorias y doy cuenta de eso en mi trabajo. La imagen misma de Túpac Amaru se hiper-masculiniza cuando la misma noción del Amaru pre-colombino es una noción hermafrodita, ambivalente. El

\footnotetext{
${ }^{45}$ La primera etapa del Gobierno Revolucionario de las Fuerzas Armadas fue liderada por Juan Velasco, militar que llegó al poder mediante un golpe de Estado en 1968 y emprendió un proceso de modernización del país promoviendo una reforma agraria y una reforma educativa.
} 
hecho de masculinizar el ícono pre-colombino responde a un orden colonizador blanco. ${ }^{46}$

Encontré en internet una expresión muy didáctica de transfobia y homofobia en sectores de la izquierda peruana:

Pero la exposición artística de Javi Vargas Sotomayor abre una brecha innecesaria entre quienes respetamos la imagen de Túpac Amaru y quienes le imponen una identidad de género que nunca tuvo para "desacralizarlo" (...) Increíblemente, no pocos intelectuales pequeñoburgueses que se consideran antisistémicos y contestatarios, se solidarizan con la burla y el escarnio que hace Javi Vargas Sotomayor. (...) Parece que muchos se ponen de acuerdo en descuartizar nuestra identidad, unos, desde la represión estatal y otros, desde el eclecticismo burgués travestido de arte (Castro, 2010).

Sobre la idea de de-construir la imagen del héroe masculinizado, Javi comenta:

Fue surgiendo de a poco, pero me queda mucho más claro después del encuentro con Giuseppe Campuzano. ${ }^{47}$ (...) Giuseppe me muestra un texto que él había investigado del cronista Juan Santa Cruz Pachacuti que da cuenta de ciertas claves mitológicas según las cuales el Chuquichinchay es un felino protector de indios hermafroditas que había estado presente en el nacimiento de Túpac Amaru. ${ }^{48}$

Después de revisar aspectos poéticos y políticos de la Tupi es bueno recordar que aunque el motivo ha estado presente en espacios tradicionales de arte, su aparición se dio en prácticas de artivismo y militancia. Dice Javi Vargas: "Creo que responde a una necesidad de entrar en contacto con la gente. No emerge como una gráfica para una galería sino como una gráfica para ponerse en la calle". ${ }^{49}$ La Tupi es un potente ejemplo de disidencia sexual y trasgresión simbólica, es arte crítico en el sentido que Chantal Mouffe (2014, p. 98) da al término: una apuesta artística que busca alterar la hegemonía dominante, su presencia en el Foro de la Cultura Solidaria interpeló las ideologías normalizadas, disputó y cuestionó desde los mismos espacios anti-capitalistas de izquierda sin dejar de trabajar por la articulación entre distintas agendas de lucha social y política.

\footnotetext{
46 J. Vargas, comunicación personal, 27 de septiembre de 2019.

${ }^{47}$ Giuseppe Campuzano (1969 - 2013) fue un artivista investigador del travestismo en Perú.

48 J. Vargas, comunicación personal, 27 de septiembre de 2019.

49 J. Vargas, comunicación personal, 27 de septiembre de 2019.
} 


\section{Referencias}

Castro, D. (27 de julio de 2010) Perú: Defensa de la imagen de Túpac Amaru [Mensaje en un Blog]. Mariátegui, la revista de las ideas. Recuperado de:

https://mariategui.blogspot.com/2010/07/peru-defensa-de-la-imagen-de-tupac.html

Colectivo ContraNaturas (10 de agosto de 2009) Rechazo frente al acto de censura que ha sufrido la exposición "La falsificación de las Túpac" [Mensaje en un Blog]. Colectivo ContraNaturas. Recuperado de:

http://colectivoContraNaturas.blogspot.com/2009/08/ [Consulta: 12 agosto 2020].

De la Puente, Roberto [Jorge Miyagui] (2019, 24 de noviembre) II Foro de la Cultura Solidaria de Villa El Salvador 2005.

https://www.youtube.com/watch?v=IEjJruqa0eM [Consulta: 12 agosto 2020].

García, Ramiro [Ramiro García] (s.f.) Murales Foro Cultura Solidaria - Villa El Salvador 2009. https://www.youtube.com/watch?v=gUCE8AxGx3k [Consulta: 12 agosto 2020].

Jaime, Martín (2019) Estéticas maricas. Representaciones sobre la diversidad sexual en las prácticas estéticas en Perú (2000-2015). (Informe de Investigación). Universidad Andina Simón Bolívar, Quito, Ecuador.

Mouffe, Chantal (2014) Agonistica: pensar el mundo políticamente. Buenos Aires: Fondo de Cultura Económica de Argentina.

Walker, C. (2015) La rebelión de Tupac Amaru. Lima, Perú: Instituto de Estudios Peruanos.

Enviado: 2020-10-05

Aceptado: 2020-12-06 